\title{
A new MPPT technique for optimal and efficient monitoring in case of environmental or load conditions variation
}

\author{
Bennacer EL HASSOUNI ${ }^{1}$, Abdellatif G.AMRANI ${ }^{1}$, Ali HADDI ${ }^{2}$ \\ ${ }^{1}$ Advanced science and technology laboratory, University of ABDELMALEK ESSAÄDI, FPL of Larache, Morocco \\ ${ }^{2}$ Innovative Technologies Laboratory (LTI), University of ABDELMALEK ESSAÄDI, (ENSAT) Tetouan, Morocco
}

\begin{abstract}
Information Technology (IT) services have become an inherent component in almost all sectors. Similarly, the health sector has been recently integrating IT to meet the growing demand for medical data exchange and storage. Currently, cloud has become a real hosting alternative for traditional on-permise software. In this model, not only do health organizations have access to a wide range of services but most importantly they are charged based on the usage of these cloud applications. However, especially in the healthcare domain, cloud computing deems challenging as to the sensitivity of health data. This work aims at improving access to medical data and securely sharing them across healthcare professionals, allowing real-time collaboration. From these perspectives, they propose a hybrid cryptosystem based on AES and Paillier to prevent the disclosure of confidential data, as well as computing encrypted data. Unlike most other solutions, the proposed framework adopts a proxy-based architecture to tackle some issues regarding privacy concerns and access control. Subsequently, this system typically guarantees that only authorized users can view or use specific resources in a computing environment. To this aim, they use eXtensible Access Control Markup Language (XACML) standard to properly design and manage access control policies. In this study, they opt for the (Abbreviated Language for Authorization) ALFA tool to easily formulate XACML policies and define complex rules. The simulation results show that the proposal offers simple and efficient mechanisms for a secure use of cloud services within healthcare domain. Consequently, this framework is an appropriate method to support collaboration among all entities involved in medical information exchange.
\end{abstract}

Keywords: Cloud computing, medical data, security, access control.

\section{INTRODUCTION}

The maximization of photovoltaic power remains a great challenge for researchers. Several MPPT algorithms have been developed to maximize PV generators' power, namely FSCC, FOCV, Fuzzy Logic, Artificial Neuron Array, P\&O, and INC $[1,2]$. The FSCC and FOCV methods represent the simplest MPPT algorithms, which are based on the linearity of the open-circuit voltage or short-circuit current with respect to the voltage or current, respectively, at the point of maximum power. In contrast, these techniques isolate the PV array to measure the noload voltage or short-circuit current. Therefore, the energy loss is higher due to this periodic isolation [3].

Fuzzy logic and artificial neural network algorithms, on the other hand, are control methods based on learning and whose implementation requires precise knowledge. Fuzzy logic and artificial neural network are very efficient in MPP monitoring, and they provide a consistent MPPT algorithm thanks to their ability to handle the non-linearity of the PV generator. However, they require a large memory capacity for computation and rule implementation. Indeed, the fuzzy logic method requires the developer to have some prior knowledge of how the output responds qualitatively to the inputs, and it suffers from the serious drawback that the rules cannot be modified once they are defined. The artificial neural network method has many drawbacks, such as the fact that the data necessary for the training process must be acquired for each PV panel and installation and that the characteristics of PV systems change over time so that the neural network requires periodic training. Therefore, since the amount of training required is quite high for this algorithm, it makes its implementation even more complex [4].

On the other hand, P\&O and INC methods are the most frequently used. These techniques exploit the powervoltage characteristic of the $\mathrm{P}(\mathrm{V})$ photovoltaic panel. In the case of the $\mathrm{P} \& \mathrm{O}$ technique, steady-state oscillations occur after the maximum power point (MPP) is detected due to the disturbance this technique generates to maintain the MPP, which increases the power loss [5]. For the INC technique, it is, in fact, based on the fact that the slope of the $\mathrm{P}(\mathrm{V})$ characteristic is equal to zero at the maximum power point, and theoretically, there is no perturbation after the MPP is discovered. Therefore, oscillations are minimized. On the other hand, during commissioning, the value zero is barely found on the $P(V)$ slope due to the truncation error in digital processing. Thus, the INC 
technique may give an incorrect response when the solar irradiation or the load changes rapidly.

When solar irradiation or load resistance changes rapidly, the fixed-pitch $\mathrm{P} \& \mathrm{O}$ and INC algorithms' responses are slow. Thus, the variable-pitch $\mathrm{P} \& \mathrm{O}$ and INC algorithms are proposed in $[6,7]$ to overcome this problem. However, the step size becomes smaller when the operating point is close to the maximum power point (MPP) [8].

Some modified algorithms have been introduced to optimize the convergence speed during the variation of power, solar irradiation, and load. A new MPPT technique is introduced in [9], which exploits the MPP locus described in [10] and the short-circuit current, load current, and voltage to follow the MPP. The process of determining the short-circuit current and open-circuit voltage results in considerable power loss and low efficiency. A fast convergence algorithm is proposed in [11,25] that uses the relationship between the load line and the current-voltage curve I(V) of the PV generator. However, its tracking speed is slightly slower due to the increase in solar radiation, and thus, this first phase improves the tracking speed.

In this working framework, a further improvement of the MPPT technique based on the Incremental Conductance Algorithm (INC) is proposed to efficiently track the point of maximum power in case of rapid changes in solar irradiation or load. The proposed algorithm is composed of two main phases, namely the follow-up phase and the regulation phase.

The follow-up phase consists of two calculation blocks (Block_A \& Block_B), allowing to generate an initial value of the duty cycle according to the characteristics of the $\mathrm{I}(\mathrm{V})$ curve and the characteristics of the DC-DC converter. The duty-cycle ratio generated during this follow-up is normally close to the MPP duty-cycle ratio, which improves the response speed.

The control phase regulates the duty cycle using small steps and is carried out until the defined stabilization condition is met (condition definition afterward). This phase improves efficiency by ensuring that the operating point is always at or near the MPP.

\section{THE MPPT SYSTEM}

\section{A. The need for the MPPT controller}

The photovoltaic generator gives the characteristics of the $\mathrm{I}(\mathrm{V})$ and $\mathrm{P}(\mathrm{V})$ curves shown in Figure 1. These characteristics highlight a point where the power is maximum (MPP). As presented above, this point depends on several parameters, such as solar irradiation and temperature. Also, the characteristic of the load is generally different from the MPP. Therefore, the Boost converter controlled by the duty cycle $(\alpha)$ generated by the MPPT controller is placed between the PV array and the load. The purpose of this addition is to provide source-load matching between the PV array and the load to allow the PV array to provide maximum power and otherwise operate at MPP.

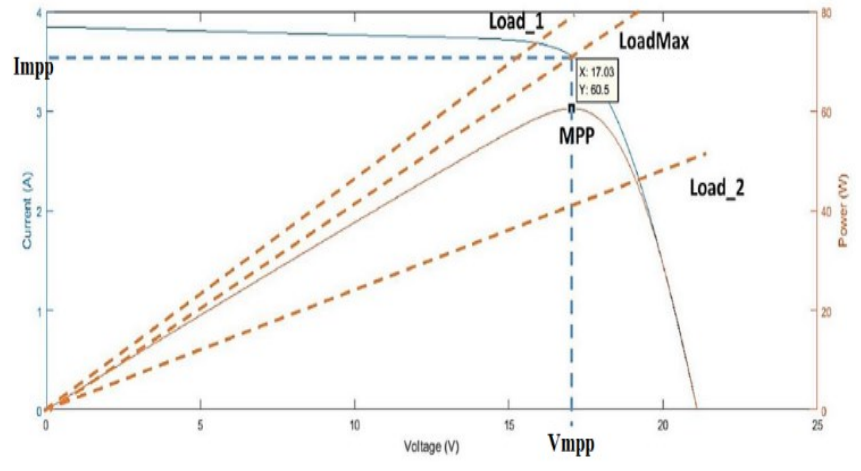

Figure 1. Impact of Load on PV Generator Characteristics

\section{B. Design of the DC-DC converter (Boost)}

\section{1) Presentation}

The Boost converter is designed to convert the DC input voltage $(V \mathrm{e})$ to another $\mathrm{DC}$ voltage $(V \mathrm{~s})$. As shown in Figure 2, this converter has a MOSFET switch controlled by a PWM signal. When the switch switches to open mode, the inductor stores the energy supplied by the PV panel. In addition, the reverse-biased diode isolates the output of the $\mathrm{PV}$ generator, and the output capacitor provides the current to the load. However, if the switch is closed, the inductor discharges, and the forward-biased diode connects the output to the PV generator. The voltage of the PV array and the coil (discharged state) contribute to the output voltage; therefore, it is always higher than the input voltage $[12,13]$.

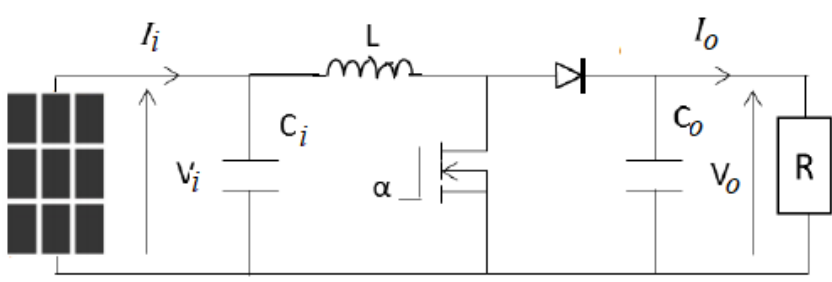

Figure 2. Boost Converter Electrical Diagram

The operating principle of the boost converter is described by equations 1 and 2 below [16, 17] :

$$
\begin{gathered}
V_{o}=\frac{V_{i}}{(1-\alpha)} \\
I_{o}=I_{i}(1-\alpha) \\
V o \times I o=V p v \times I p v
\end{gathered}
$$

Using equations 1 and 2, we obtain equation 4, representing the relationship between the PV generator's resistance (Req) and the load resistance $(R \mathrm{sh})$. Based on this equation, the MPPT controller can find the optimal value of the duty cycle $(\alpha)$ to remove the offset between the load and the MPP. Therefore, the boost converter is critical to obtain the maximum power available at the panel output. 


$$
R_{e q}=\frac{V_{i}}{I_{i}}=\frac{V_{o}(1-\alpha)^{2}}{I_{o}}=R_{s h}(1-\alpha)^{2}
$$

\section{2) Boost sizing}

After any calculation is made, finally, the Boost converter's configuration used in the continuation of this work is detailed in the table below.

TABLE I. BOOST CONVERTER CONFIGURATION

\begin{tabular}{cc}
\hline \hline Settings & Value \\
\hline \hline $\mathrm{L}$ & $1.25 \mathrm{mH}$ \\
\hline $\mathrm{Ci}$ & $70 \mu \mathrm{F}$ \\
\hline $\mathrm{Co}$ & $70 \mu \mathrm{F}$ \\
\hline $\mathrm{f}$ & $10 \mathrm{kHz}$ \\
\hline $\mathrm{R}$ & $80 \Omega$ \\
\hline
\end{tabular}

\section{LIMITATIONS OF THE INC ALGORITHM}

An excellent MPPT algorithm allows us to find an agreement between tracking speed and steady-state performance.

Following these requirements, the INC algorithm is usable even though it may fail in some cases [17], and in the course of this work, it will be improved in order to enhance its performance. The INC algorithm is based on the fact that the slope of the $\mathrm{P}(\mathrm{V})$ characteristic is zero at the point of maximum power [18]. Therefore, this algorithm can be modeled as follows:

$$
\begin{gathered}
\frac{d P}{d V}=0 \text { At the MPP } \\
\frac{d P}{d V}>0 \quad \text { To the left of the MPP } \\
\frac{d P}{d V}<0 \quad \text { To the right of the MPP }
\end{gathered}
$$

Since:

$$
\frac{d P}{d V}=\frac{d(I V)}{d V}=V \frac{d I}{d V}+I
$$

So:

$$
\begin{gathered}
\frac{d I}{d V}=-\frac{I}{V} \quad \text { At the MPP } \\
\frac{d I}{d V}>-\frac{I}{V} \quad \text { To the left of the MPP } \\
\frac{d I}{d V}<-\frac{I}{V} \quad \begin{array}{c}
\text { To the right of the } \\
\text { MPP }
\end{array}
\end{gathered}
$$

The flowchart of the INC algorithm is shown in Figure 3 [18]. This algorithm measures the current and voltage of the PV array. If equation ten is satisfied, the duty cycle is increased, and vice versa if equation 11 is satisfied. Thus, there is nothing to do if equation 9 is satisfied. Theoretically, if the maximum power point is reached, there is no more disturbance of the duty cycle. Thus, steady-state oscillations are reduced, and this is the main advantage of this algorithm.

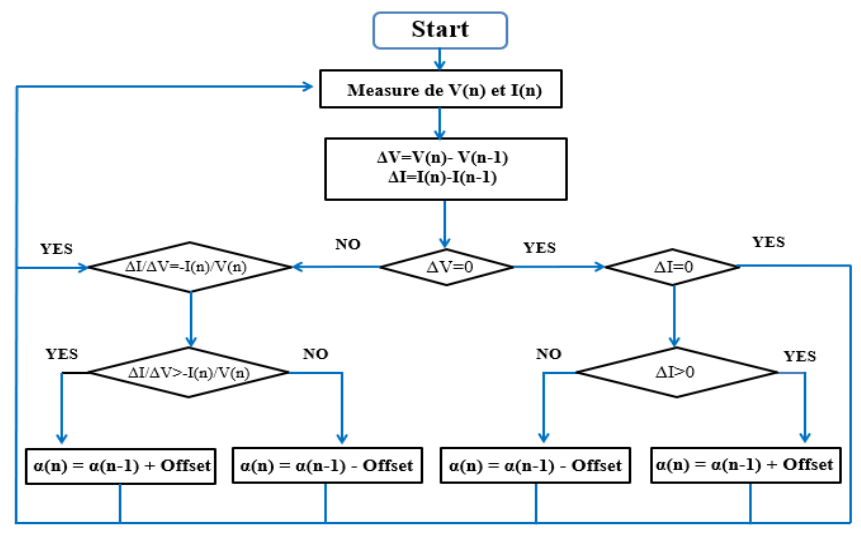

Figure 3. The flowchart of the classical INC algorithm

The classical algorithm does not make the right decision when the irradiation is suddenly increased [16]. As shown in Figure 4, when the solar irradiation is 400 $\mathrm{W} / \mathrm{m}^{2}$, and the PV system is powering Load 1, the INC technique allows controlling the PV system to reach the MPP (point B).

When solar radiation is suddenly increased to 900 $\mathrm{W} / \mathrm{m}^{2}$, load 1 drives the system to point $\mathrm{G}$ of characteristic $\mathrm{I}(\mathrm{V})$, which coincides with point $\mathrm{C}$ of characteristic $\mathrm{P}(\mathrm{V})$. The INC technique calculates the slope between point $\mathrm{C}$ and point $\mathrm{B}$, which is positive. Therefore, the INC algorithm will decrease the duty cycle, and the voltage of the PV array will be increased. Nevertheless, since the MPP of $900 \mathrm{~W} / \mathrm{m}^{2}$ corresponds to point $\mathrm{A}$, and the slope between points $\mathrm{A}$ and $\mathrm{C}$ is negative, the $\mathrm{PV}$ array voltage should be decreased to reach point $\mathrm{A}$, instead of increasing the voltage and moving away from point $\mathrm{A}$ as the classical INC algorithm does. Usually, when the solar irradiation increases, the MPP moves to the right, and, therefore, the same problem occurs.

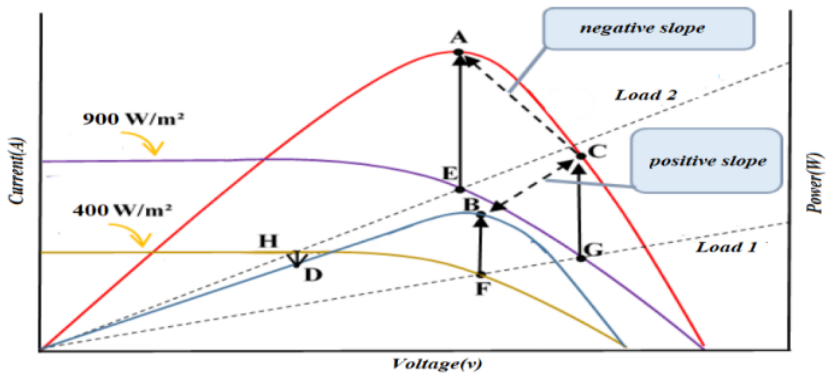

Figure 4. PV panel behavior for $900 \mathrm{~W} / \mathrm{m}^{2}$ and $400 \mathrm{~W} / \mathrm{m}^{2}$ irradiations 
Conversely, this failure of the Incremental Conductance algorithm does not occur if solar irradiation is reduced. Because as shown in Figure 4, the slope is positive between points $\mathrm{A}$ and $\mathrm{D}$ and also between points $\mathrm{B}$ and $\mathrm{H}$.

To summarize, the energy from the PV panel with a larger step size of the INC algorithm contributes to faster dynamics but excessive oscillations when a steady state is reached, resulting in relatively low efficiency [7]. Thus, convergence speed is low when this algorithm follows the MPP with a smaller step size.

\section{THE PROPOSED NEW MPPT TECHNIQUE}

\section{A. Foundation}

In order to overcome the previously described problem of the classical INC method, a new MPPT algorithm is proposed in the following. This new method has two complementary treatment phases, the follow-up phase, and the control phase. In the first phase, an initial value of the duty cycle is generated as a function of the current-voltage characteristics $\mathrm{I}(\mathrm{V})$ of the PV generator and the boost converter characteristics. In the second phase (control phase), the duty cycle is regulated by applying a small step size. Therefore, the follow-up phase is likely to improve the response speed. The control phase can also improve efficiency by ensuring that the operating point is always at or near the MPP.

By replacing the term Ppv $=\mathrm{Vpv} x \mathrm{Ipv}$ in equations 2 and 3 (equations characterizing the boost converter), we obtain:

$$
\begin{gathered}
I_{o}=\frac{V_{p v} I_{p v}}{V_{o}}=\sqrt{\frac{P_{p v} I_{o}}{V_{o}}} \\
\alpha=\frac{I_{p v}-I_{o}}{I_{p v}}
\end{gathered}
$$

According to equations 12 and 13, if the variable Ppv is the maximum photovoltaic power MPPP, the variable $\alpha$ obtained from equation 13 corresponds to the duty cycle to MPPP. Then, the maximum PV power PMPP can be considered as the product of the short-circuit current Icc and the voltage at MPP (VMPP) as shown in [19]:

$$
P_{M P P}=V_{M P P} I_{M P P} \approx V_{M P P} I_{C C}
$$

If we substitute equation 14 in equations 12 and 13 , we obtain:

$$
\begin{gathered}
I_{O(P P M)}=\sqrt{\frac{V_{M P P} I_{M P P} I_{O}}{V_{O}}} \approx \sqrt{\frac{V_{M P P} I_{C C} I_{O}}{V_{O}}} \\
\alpha=\frac{I_{M P P}-I_{O(M P P)}}{I_{M P P}} \approx \frac{I_{C C}-I_{O(M P P)}}{I_{C C}}
\end{gathered}
$$

The value of the duty cycle $\alpha$ obtained by equation 16 is close to the MPP duty cycle. However, the variables VMPP and Icc in equation 15 are not known. According to [10], the variable VMPP can be replaced by the previously monitored MPP voltage. To obtain the variable Icc, the method proposed in [19] is used, according to which the switch of the DC-DC converter is kept open for a certain time. Although this method allows obtaining a very accurate Icc value, this treatment results in high power losses. With this method, it is possible to find the approximate value of the Icc or IMPP value as a function of the variation of the operating point during fluctuations in solar irradiation or load resistance.

\section{B. Algorithm of the proposed method}

Based on the previous analyses, the relationship between the voltage and current of the PV generator and the solar irradiation or load resistance is summarized in the following table.

TABLE II. VARIATION OF THE GPV VOLTAGE AND CURRENT DURING IRRADIATION/LOAD VARIATION

\begin{tabular}{ccccc}
\hline \hline & \multicolumn{2}{c}{ Solar irradiation } & \multicolumn{2}{c}{ Load } \\
\hline \hline & Increase & Decrease & Increase & Decrease \\
\hline $\begin{array}{c}\text { Voltage } \\
\text { variation }\end{array}$ & + & - & + & - \\
\hline $\begin{array}{c}\text { Current } \\
\text { variation }\end{array}$ & + & - & - & + \\
\hline
\end{tabular}

The overall flowchart of the proposed algorithm is shown in Figure 5.

The two variables G+ and G- correspond respectively to the increase and decrease in solar irradiation level. In addition, when the load resistance increases and decreases, the variables $\mathrm{CH}+$ and $\mathrm{CH}-$ are set to 1 , respectively. The variable $\mathrm{PM}$ is used to indicate that the PV array is operating at maximum power if it is set to the value of 1 .

Since equation 9 can never be practically satisfied [20], an uncertainty (called Ince in the diagram) is accepted to detect whether the point of maximum power is reached, according to equation 17 [21]:

$$
\left|\frac{I}{V}+\frac{\Delta I}{\Delta V}\right|<0.04
$$

In order to improve the efficiency of the system by ensuring that the operating point is always at or near the MPP, equation 18 is proposed (minimizing the uncertainty from 0.04 to 0.02 ).

$$
\left|\frac{I}{V}+\frac{\Delta I}{\Delta V}\right|<0.02
$$

The duty-ratio step of the Boost converter has been increased from 0.012 to 0.006 to give more stability in a 
steady-state; this phase is that of the regulation (control phase) of the proposed technique.

When the condition of equation 17 is met, but the condition of equation 18 is not met, the control phase is carried out as shown in Figure 5(a). Initially, the proposed technique follows the MPP using the classical Incremental Conductance technique. When the maximum power point is reached (i.e., the condition of equation 17 is satisfied), the current and voltage of the MPP are stored in VMPP and IMPP, respectively, and the variable PM is set to 1 . If equation 18 is not satisfied at the next sampling cycle, the control phase of the proposed technique is performed, and vice versa if this equation's criterion is met.

When the condition of equation 17 is not met, and the variable PM is equal to 1 , the "Block_A" subroutine of the follow-up phase of the proposed new method is called Figure 5(b). Then, the variable PM is set to zero, and the variables Vs and Is are calculated using equations 1 and 2, respectively. Subsequently, the change in solar irradiation or load resistance is detected using the change in current and voltage $\Delta \mathrm{I}$ and $\Delta \mathrm{V}$. Finally, the duty cycle is updated if an increase in solar irradiation is detected.

In the next sampling cycle, the proposed technique calculates the values of Vs and Is and uses the "Block_B" subprogram as shown in Figure 5(b). This subroutine is part of the follow-up phase of our proposed new method. In this sub-program, the duty cycle is updated by different equations according to solar irradiation and load resistance variation.

Once the "Block_B" subroutine is executed, the operating point approaches the MPP. Therefore, the tracking phase, including the "Block_A" and "Block_B" subprograms, can improve the tracking speed. At the next sampling cycle, if the condition in equation 17 is not met, the proposed technique adjusts the duty cycle using a large step (step $=0.012)$. When 17 is reached and 18 is not reached, the follow-up phase is used with a small step (step $=0.006$ ) until equation 18 is satisfied.

\section{SimUlations AND RESULTS}

Figure 6 shows the simulation model on the MATLAB/Simulink environment of the proposed new method. It includes a photovoltaic generator (array of several modules), a DC-to-DC booster converter, an MPPT controller (the proposed new technique), and a resistive load. The PV generator comprises a series array of two DCSolar-100 modules (Leading Edge Power brand) whose main technical characteristics are presented in Table 2.

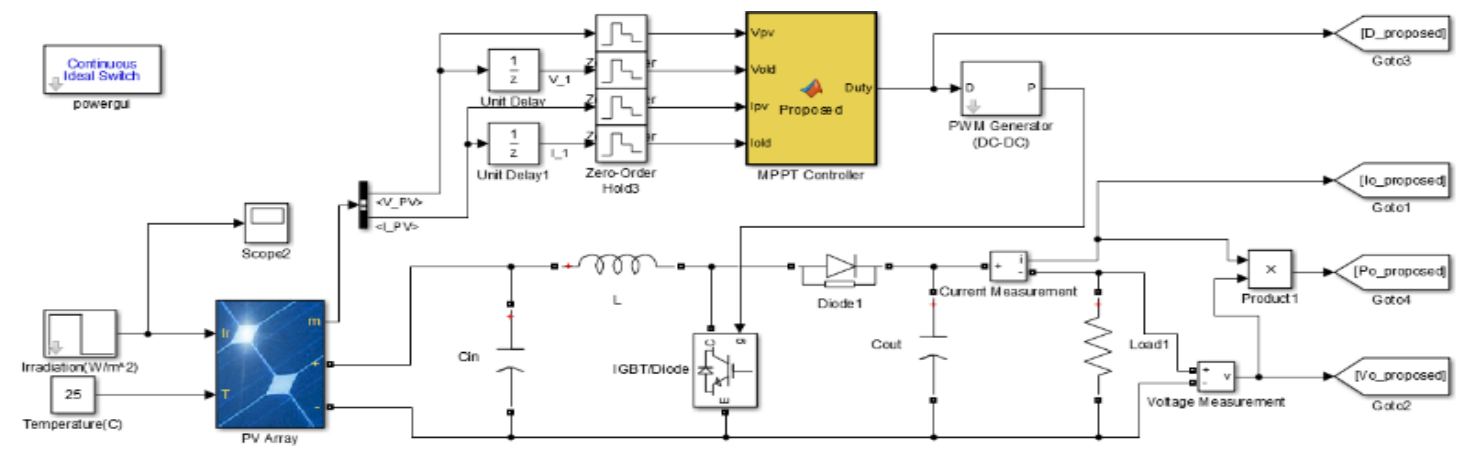

Figure 6. Simulink Model of the New MPPT Technique.

TABLE III. DC-SOlaR-100 PV MOdule DATA SHEET

\begin{tabular}{cc}
\hline \hline PV Panel Settings & Value \\
\hline \hline Maximum power Pmpp & $100 \mathrm{~W}$ \\
\hline Voltage at maximum power Vmpp & $17.5 \mathrm{~V}$ \\
\hline Current at maximum power Impp & 5,72 \\
\hline Open circuit voltage Voc & $21.2 \mathrm{~V}$ \\
\hline Short-circuit current Icc & $5.78 \mathrm{~A}$ \\
\hline Voltage/temperature coefficient kv & $-0,32 \% /{ }^{\circ} \mathrm{C}$ \\
\hline Current/temperature coefficient ki & 0,0892 \\
\hline Number of cells & 36 \\
\hline Type & Monocrystalline \\
\hline
\end{tabular}

The Boost converter is designed for source-load impedance matching mode with the technical specifications mentioned in the above-mentioned Table 2.

A simulation comparison of the proposed new MPPT method with other techniques, including the classical incremental conductance technique (INC) [22] and the modified variable-size incremental conductance technique (M-INC) [7] is performed in three different situations. These situations include a rapid variation of high-intensity solar irradiance, a rapid variation of low-intensity solar irradiance, and load variation.

\section{A. Rapid variation of solar irradiation (high intensity)}

Figure 7 shows the simulation result for this case, where the solar irradiation level is abruptly increased from 500 $\mathrm{W} / \mathrm{m} 2$ to $1000 \mathrm{~W} / \mathrm{m} 2$; the data characterizing this simulation situation are grouped in the following table: 
TABLE IV. SIMULATION CONDITIONS IN CASE OF RAPID CHANGE OF IRRADIATION (HIGH INTENSITY)

\begin{tabular}{|lccc|}
\hline \hline \multicolumn{1}{|c|}{ Time (s) } & $0 \rightarrow 0,8$ & $0.8 \rightarrow 2,8$ & $2.86 \rightarrow$ \\
\hline \hline $\begin{array}{l}\text { Solar irradiation } \\
\left(\mathrm{W} / \mathrm{m}^{2}\right)\end{array}$ & 500 & 1000 & 500 \\
\hline Temperature $\left({ }^{\circ} \mathrm{C}\right)$ & & 25 & \\
\hline $\operatorname{Load}(\Omega)$ & 80 \\
\hline
\end{tabular}

The classical INC method is the one that takes the longest time to follow the point of maximum power, as shown in Figure 7. When the irradiation level is increased to $1000 \mathrm{~W} / \mathrm{m} 2$, the modified INC method requires less time ( $0.41 \mathrm{~s}$ and 9 sampling cycles) to reach MPP compared to the conventional INC method (1.29 $\mathrm{s}$ and 25 sampling cycles). When the irradiation level is reduced to $500 \mathrm{~W} / \mathrm{m} 2$, the conventional M-INC and INC method takes almost the same time (1.22 s and 19 sampling cycles) to reach MPP compared to the conventional INC (1.22 s and 19 sampling cycles).

The proposed technique takes less time $(0.35 \mathrm{~s}$ and 6 sampling cycles) to follow the maximum power point than the other two techniques when the irradiation is increased from $500 \mathrm{~W} / \mathrm{m} 2$ to $1000 \mathrm{~W} / \mathrm{m} 2$. When the irradiation is reduced to $500 \mathrm{~W} / \mathrm{m} 2$, the proposed technique takes less time ( $0.48 \mathrm{~s}$ and 7 sampling cycles) to reach MPP than the conventional INC and M-INC techniques.

However, the overall speed of convergence of the proposed technique is faster than that of the other techniques.

Figure 8 illustrates the oscillations of the 3 techniques in a steady state in the case of rapid changes in solar irradiation.

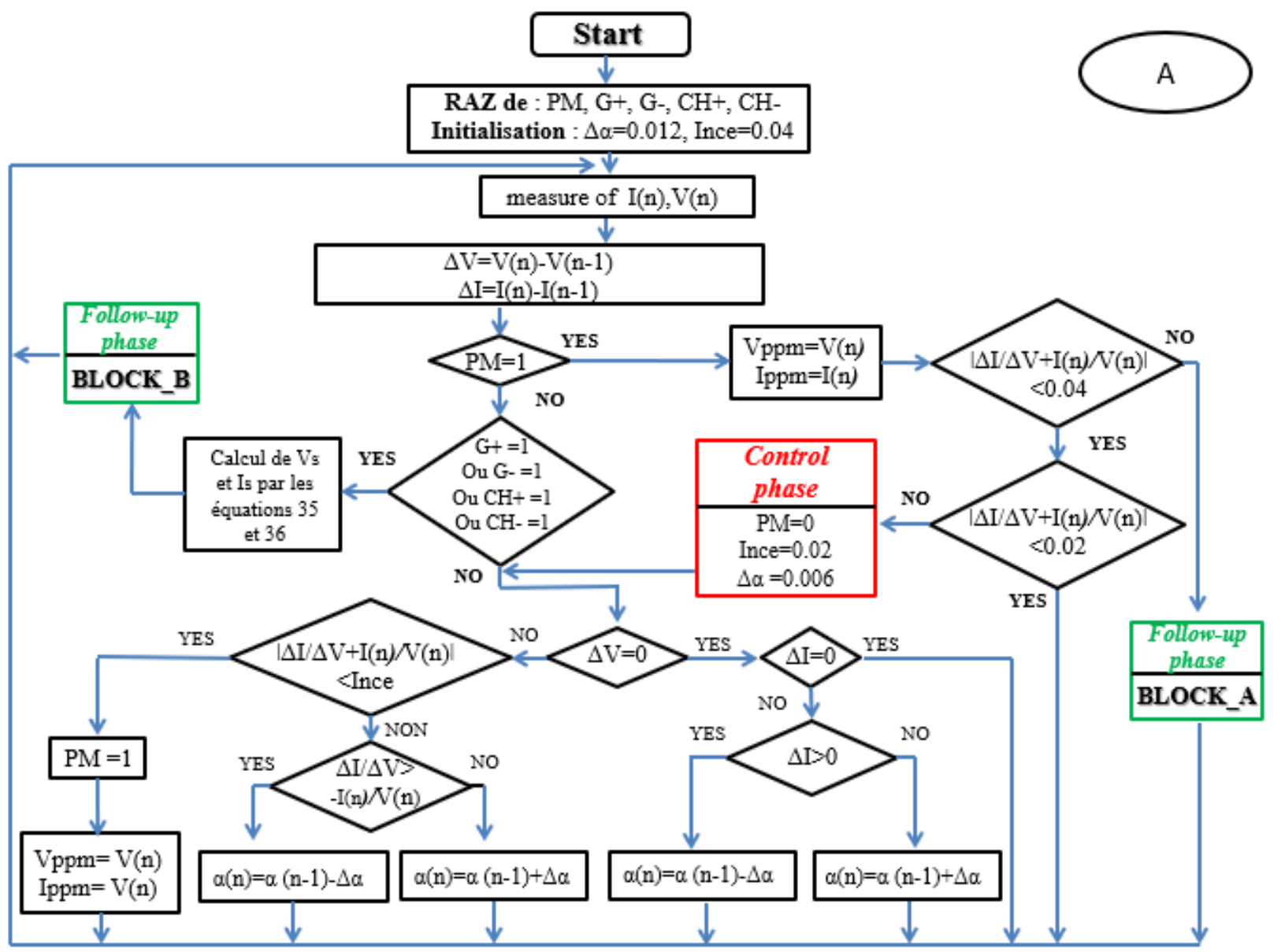




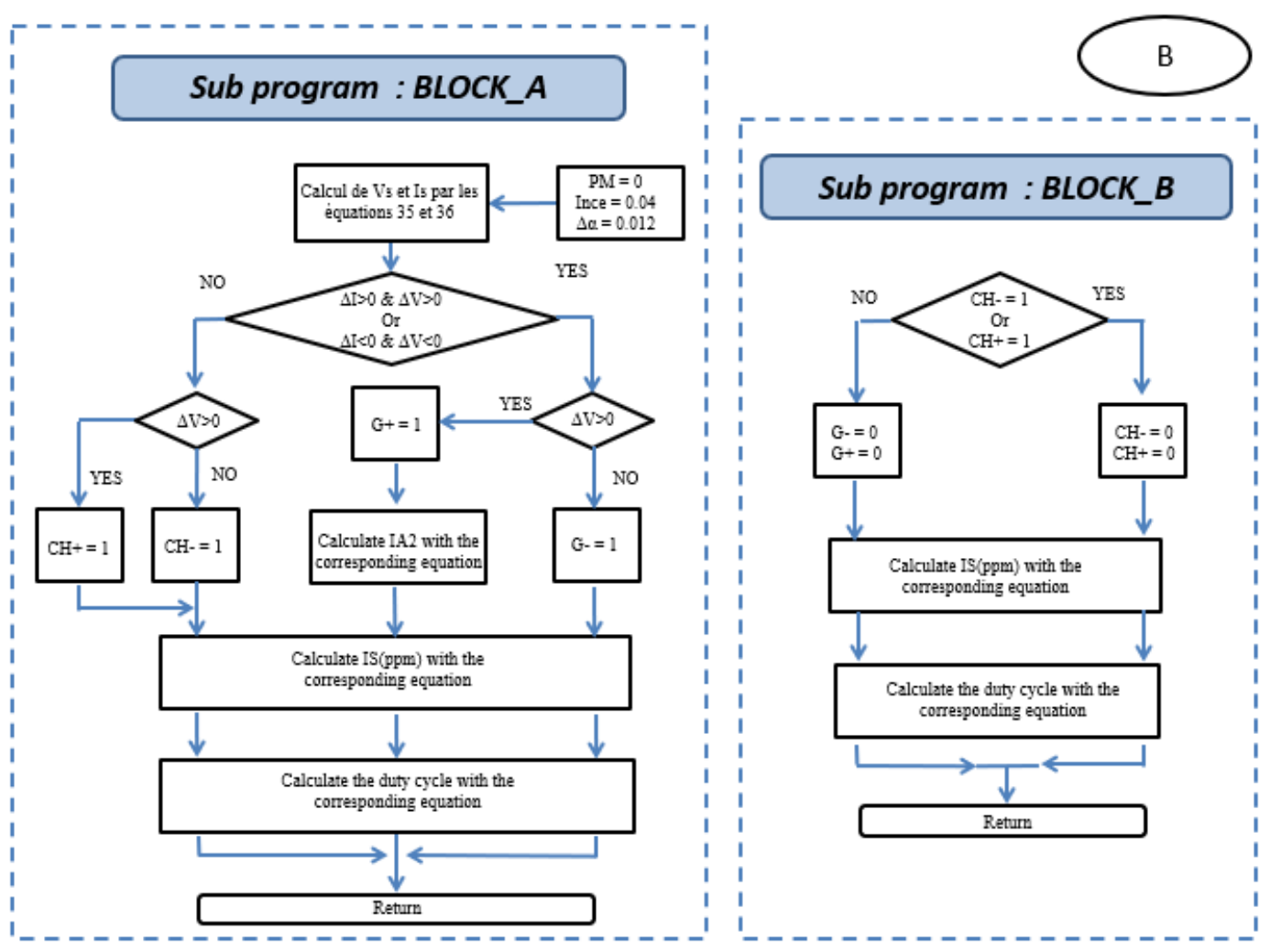

Figure 5. Flowchart of the proposed algorithm:

(A) The main program (B) The two sub-programs of the follow-up phase (Block_A \& Block_B)

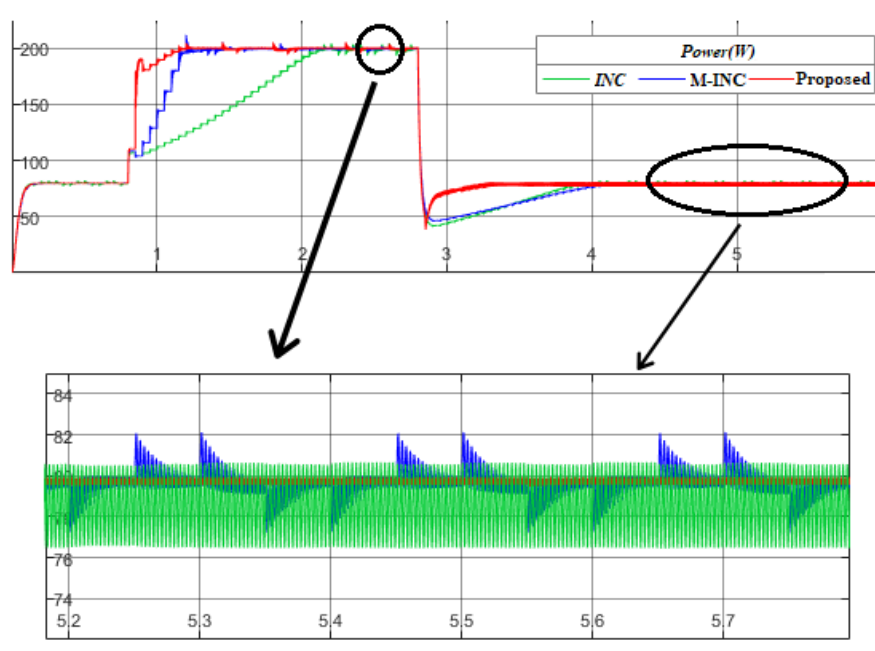

Figure 8. Steady-state oscillations in the event of rapid changes in irradiation

In a steady state, the modified INC technique's power losses are lower than those of the conventional INC technique. This is mainly since the conventional INC technique has a higher oscillation than the modified INC technique.

The proposed technique presents minimal or negligible oscillations after reaching the MPP compared to other techniques, which presents low efficiency and significant power losses for the latter two techniques. As a result, the proposed technique improves not only tracking speed but also steady-state performance.

\section{B. Rapid variation of solar irradiation (low intensity)}

Figure 9 shows the simulation result for this case, where the solar irradiation level is abruptly increased from 100 $\mathrm{W} / \mathrm{m} 2$ to $300 \mathrm{~W} / \mathrm{m} 2$. The data characterizing this simulation situation are grouped in the following table.

TABLE V. SIMULATION CONDITIONS IN CASE OF RAPID CHANGE OF IRRADIATION (LOW INTENSITY)

\begin{tabular}{|lccc|}
\hline \hline \multicolumn{1}{|c|}{ Time $(\mathbf{s})$} & $0 \rightarrow 0,8$ & $0.8 \rightarrow 2,8$ & $2.8 \rightarrow 6$ \\
\hline \hline Solar irradiation $\left(\mathrm{W} / \mathrm{m}^{2}\right)$ & 100 & 300 & 100 \\
\hline Temperature $\left({ }^{\circ} \mathrm{C}\right)$ & \multicolumn{3}{c}{25} \\
\hline Load $(\Omega)$ & 80 \\
\hline
\end{tabular}

When the solar irradiation is increased from $100 \mathrm{~W} / \mathrm{m} 2$ to $300 \mathrm{~W} / \mathrm{m} 2$, the proposed technique is the fastest since it takes $0.39 \mathrm{~s}$ to reach the maximum power point, whereas the modified technique requires $071 \mathrm{~s}$. The conventional INC technique is the slowest and takes $0.85 \mathrm{~s}$. 

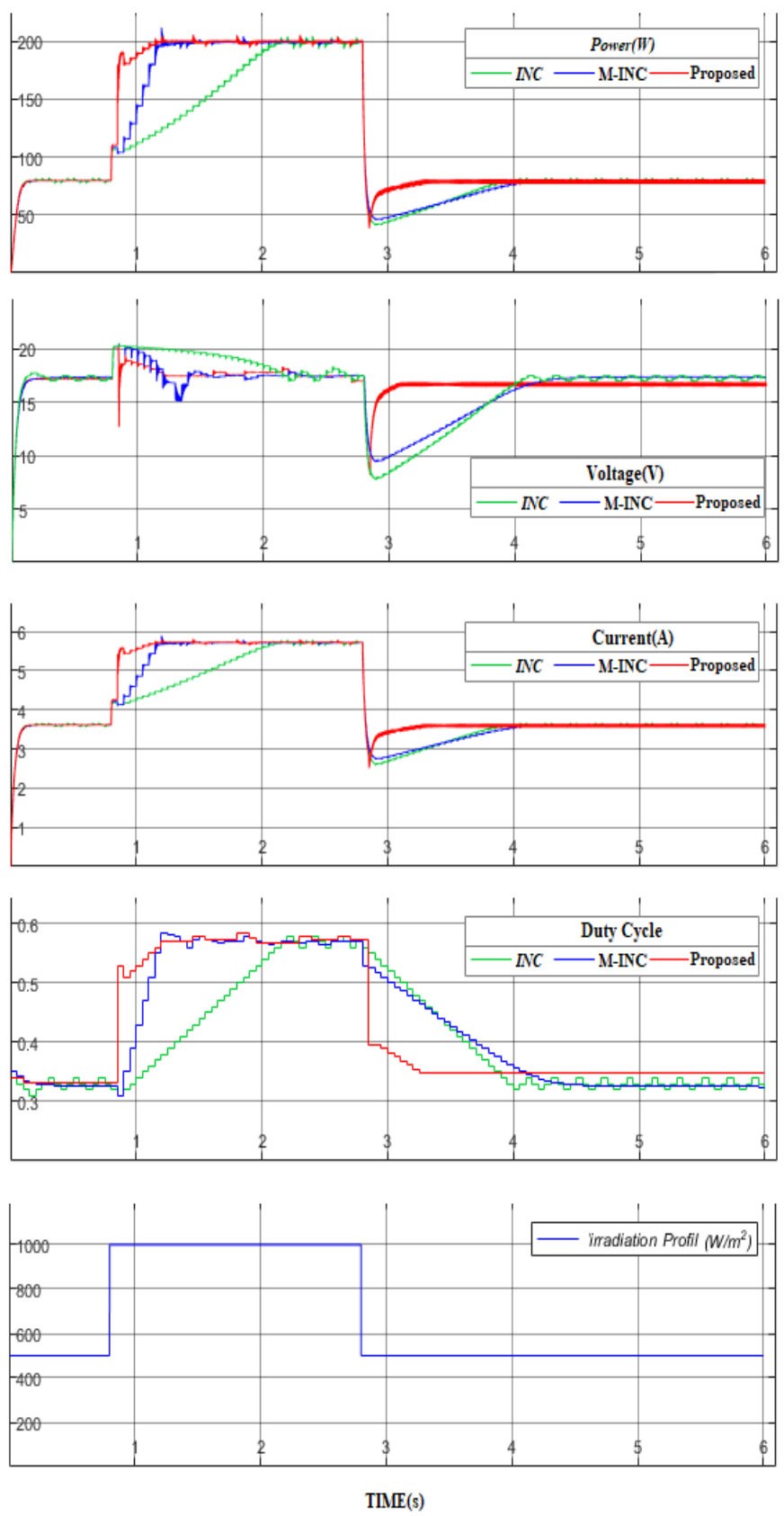

Figure 7. Simulation results for rapid variation of irradiation (high intensity)

When irradiation is reduced from $300 \mathrm{~W} / \mathrm{m} 2$ to 100 $\mathrm{W} / \mathrm{m} 2$, we notice that the 3 techniques behave almost in the same way with a small advantage from the proposed technique (when can neglect it).
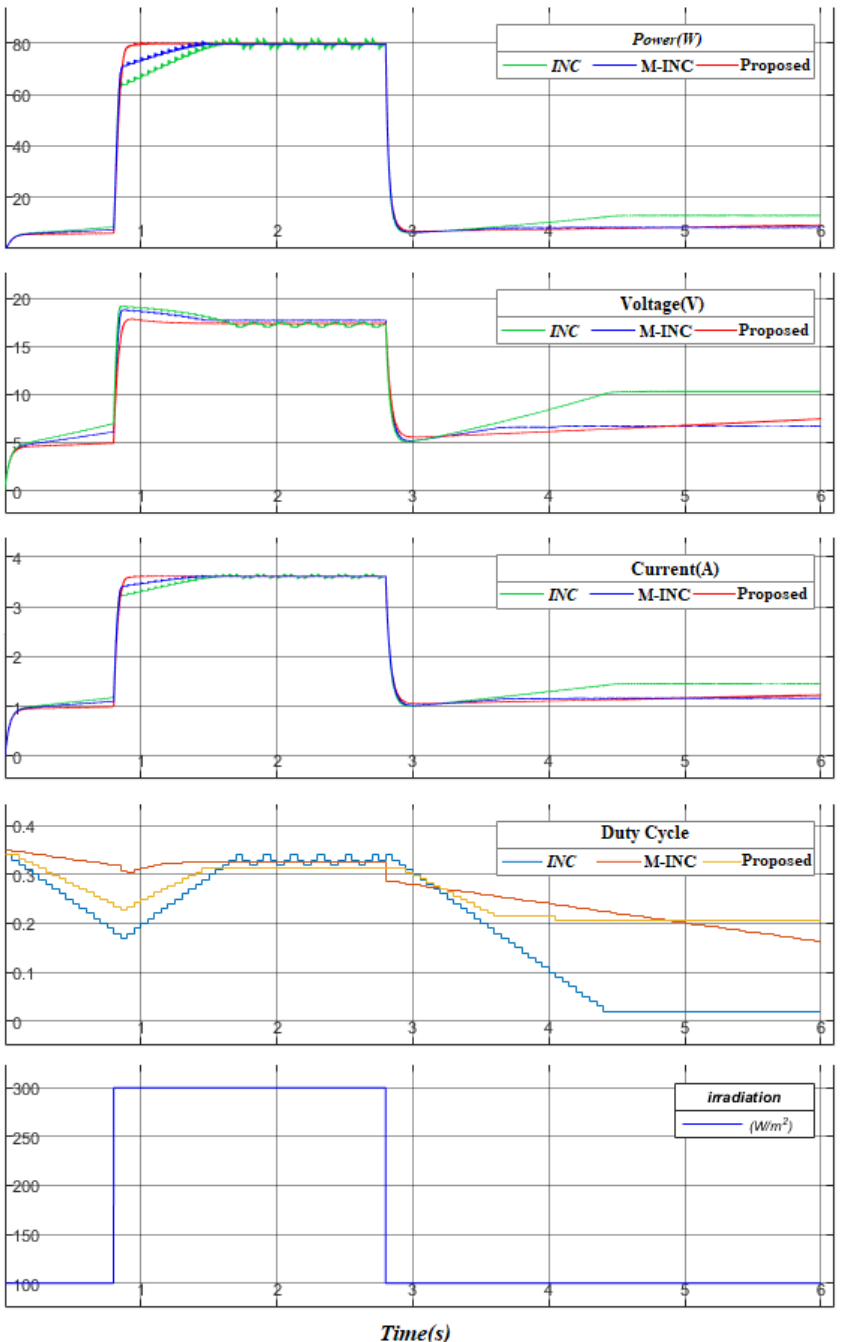

Figure 9. Simulation results for rapid irradiation variation (low intensity)

In a steady state, the proposed new method's power losses are much minimized compared to the other methods. This is mainly since the classical INC method has a larger oscillation than the modified INC method, which has larger oscillations than the proposed method as shown in Figure 9.

\section{Load variation}

Figure 10 shows the simulation result for this scenario, where the load level has been increased from $80 \Omega$ to 160 $\Omega$ and then decreased from $160 \Omega$ to $80 \Omega$; the data characterizing this simulation situation are grouped in the following table: 
TABLE VI. SIMULATION CONDITIONS IN CASE OF THE LOAD CHANGE

\begin{tabular}{|cccc|}
\hline \hline Time $(\mathbf{s})$ & $0 \rightarrow 1,2$ & $1.2 \rightarrow 3,2$ & $3.2 \rightarrow 6$ \\
\hline \hline Load $(\Omega)$ & 80 & 160 & 80 \\
\hline Temperature $\left({ }^{\circ} \mathrm{C}\right)$ & & 25 \\
\hline Solar irradiation $\left(\mathrm{W} / \mathrm{m}^{2}\right)$ & & 700 \\
\hline
\end{tabular}
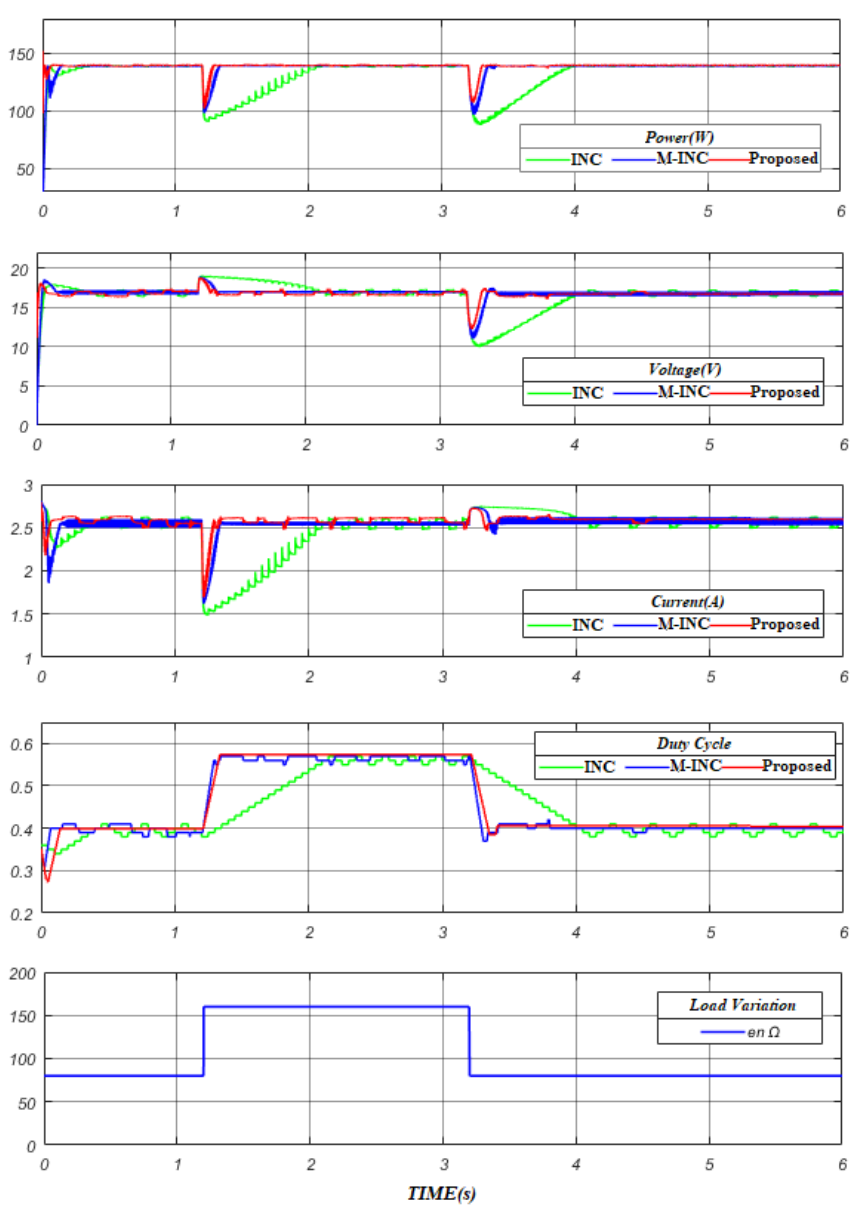

Figure 10. Simulation results for a load variation

When the load resistance is increased from $80 \Omega$ to 160 $\Omega$, the proposed method takes less time ( $0.08 \mathrm{~s})$ to reach the maximum power point than the modified technique $(0.13$ s). It should be noted that the classical method's performance remains far away since it takes almost $0.9 \mathrm{~s}$ to reach the MPP.

When the load resistance is reduced from $160 \Omega$ to 80 $\Omega$, the proposed technique takes less time $(0.11 \mathrm{~s})$ to follow the MPP than the modified technique $(0.15 \mathrm{~s})$ and the conventional INC technique $(0.8 \mathrm{~s})$. Therefore, in general, the proposed technique is the fastest in terms of overall convergence speed.
Figure 11 shows the steady-state oscillations of the 3 techniques.

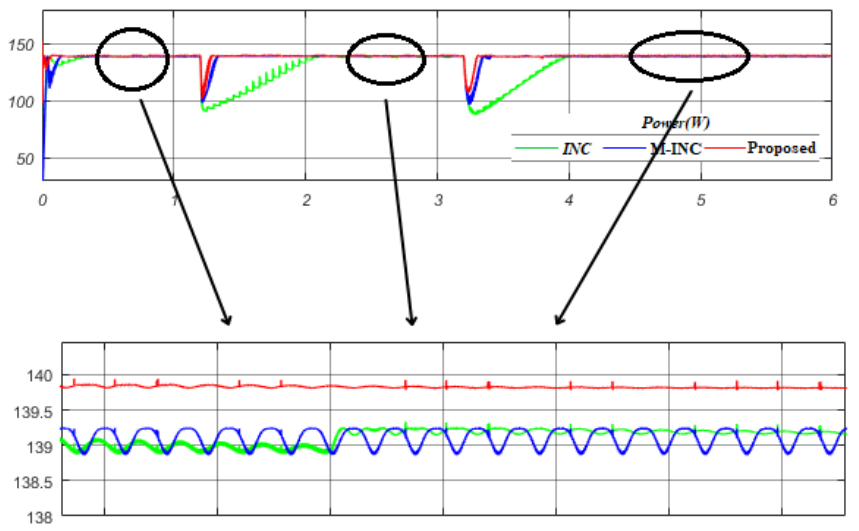

Figure 11. Steady-state oscillations under varying loads

After reaching the MPP, the proposed technique has minimal or negligible oscillations compared to the other techniques, resulting in low efficiency and significant power losses for the latter two techniques. As a result, the proposed technique improves not only tracking speed but also steady-state performance.

\section{Discussion}

In order to measure and compare the tracking efficiency and effectiveness of the techniques studied, the tracking power loss equations $P_{\text {pertes }}$ and Teff tracking efficiency are defined by (19) [23] and (20) [24], respectively.

$$
P_{\text {losses }}=\frac{\sum P_{\max }(t)-\sum P_{p v}(t)}{\sum P_{\max }(t)}
$$

Pmax is the maximum possible power under a certain irradiation level. $\mathrm{P}_{\mathrm{pv}}$ designates the power extracted by the different techniques, and $t$ designates the total tracking time required by the different methods to reach the MPP.

$$
T_{e f f}=\frac{\int_{0}^{t} P_{M P P}}{\int_{0}^{t} P_{p v}} \times 100 \%
$$

Where PMPP is the maximum power obtained by a given MPPT technique, Ppv is the theoretical power available, and $\mathrm{t}$ is the total tracking time required to reach MPP.

Table 6 presents the results of comparison of the tracking speed, steady-state oscillations, efficiency, and tracking power losses of the proposed technique compared to the other techniques, namely the conventional incremental conductance (INC) technique [22] and the enhanced variable-size incremental conductance (M-INC) technique [7].

Overall, the comparison results show the superior performance of the proposed algorithm compared to other techniques. 
In the first situation where the level of solar irradiation is suddenly increased from $500 \mathrm{~W} / \mathrm{m} 2$ to $1000 \mathrm{~W} / \mathrm{m} 2$ (under high intensity) and as shown in Table 6, it can be seen that the tracking speed of the proposed technique is 3.68 times faster than the conventional INC technique and 1.17 times faster than the modified INC technique. The tracking power loss with the proposed technique is lower than that of the other techniques, and the efficiency is increased by $14.76 \%$ and $6.17 \%$, respectively compared to the conventional INC and M-INC methods.

In the second situation where the solar irradiation level is abruptly increased from $100 \mathrm{~W} / \mathrm{m} 2$ to $300 \mathrm{~W} / \mathrm{m} 2$ (at low intensity) and as shown in Table 6 , the tracking speed of the proposed technique is 2.18 times faster than the conventional INC technique and 1.82 times faster than the modified INC technique. The loss of tracking power with the proposed technique is lower than that of the other techniques. The efficiency is increased by $14.43 \%$ and $11.68 \%$, respectively compared to conventional INC and modified INC.

TABLE VII. COMPARISON OF THE PROPOSED TECHNIQUE WITH OTHER TECHNIQUES

\begin{tabular}{|c|c|c|c|c|}
\hline Performances & Conditions & INC & $\begin{array}{c}\text { M- } \\
\text { INC }\end{array}$ & $\begin{array}{c}\text { Proposed } \\
\text { method }\end{array}$ \\
\hline \multirow{3}{*}{$\begin{array}{c}\text { Tracking speed } \\
\text { (s) }\end{array}$} & $\begin{array}{l}\text { Rapid } \\
\text { variation of } \\
\text { irradiation } \\
\text { (high } \\
\text { intensity) } \\
\end{array}$ & 1,29 & 0,41 & 0,35 \\
\hline & $\begin{array}{l}\text { Rapid } \\
\text { variation of } \\
\text { irradiation } \\
\text { (low intensity) }\end{array}$ & 0,85 & 0,71 & 0,39 \\
\hline & Load variation & 0,9 & 0,13 & 0,08 \\
\hline \multirow{3}{*}{$\begin{array}{l}\text { Steady-state } \\
\text { oscillations }\end{array}$} & $\begin{array}{l}\text { Rapid } \\
\text { variation of } \\
\text { irradiation } \\
\text { (high } \\
\text { intensity) }\end{array}$ & High & Small & Negligible \\
\hline & $\begin{array}{l}\text { Rapid } \\
\text { variation of } \\
\text { irradiation } \\
\text { (low intensity) }\end{array}$ & High & Small & Negligible \\
\hline & Load variation & High & Small & Negligible \\
\hline \multirow{3}{*}{ Yield (\%) } & $\begin{array}{l}\text { Rapid } \\
\text { variation of } \\
\text { irradiation } \\
\text { (high } \\
\text { intensity) } \\
\end{array}$ & 82,38 & 90,97 & 97,14 \\
\hline & $\begin{array}{l}\text { Rapid } \\
\text { variation of } \\
\text { irradiation } \\
\text { (low intensity) }\end{array}$ & 74,12 & 76,87 & 88,55 \\
\hline & Load variation & 93,11 & 95,97 & 98,81 \\
\hline
\end{tabular}

\begin{tabular}{c|l|c|c|c}
\hline \hline & $\begin{array}{l}\text { Rapid } \\
\text { variation of } \\
\text { irradiation } \\
\text { (high } \\
\text { intensity) }\end{array}$ & 24,5 & 16,58 & 5,86 \\
\cline { 2 - 5 } $\begin{array}{c}\text { Tracking power } \\
\text { losses (\%) }\end{array}$ & $\begin{array}{l}\text { Rapid } \\
\text { variation of } \\
\text { irradiation } \\
\text { (low intensity) }\end{array}$ & 31,09 & 30,89 & 12,75 \\
\cline { 2 - 5 } & Load variation & 13,47 & 9,96 & 6,18 \\
\hline \hline
\end{tabular}

In the load variation, the average follow-up time required by the conventional INC and modified INC techniques is $0.9 \mathrm{~s}$ and $0.13 \mathrm{~s}$, respectively, but the proposed technique requires only $0.08 \mathrm{~s}$. The tracking power loss is reduced by $7.29 \%$ compared to the conventional INC technique and by $3.78 \%$ compared to the modified INC technique.

The efficiency is increased by $1.73 \%$ and $7.73 \%$, respectively compared to conventional and modified INC techniques.

The steady-state oscillations of the proposed technique are considered negligible due to monitoring the conditions of equations 17 and 18. In terms of overall efficiency, the proposed technique is the most efficient with an efficiency of $94.83 \%$, followed by the modified technique with an overall efficiency of $87.94 \%$. The efficiency of the conventional INC technique is the lowest and does not exceed $83.33 \%$.

\section{CONCLUSION}

In this chapter, a new MPPT technique based on incremental conductance is proposed in order to efficiently follow the point of maximum power in case of rapid changes in solar irradiation or load. It includes two processing phases: the calculation phase to improve the tracking speed and the regulation phase to improve the tracking efficiency.

In order to test the performance of the proposed technique, various situations are analyzed, including the variation of solar irradiation in these two cases (high intensity and low intensity) and the variation of the load. The proposed technique is evaluated and compared with other techniques, namely the classical Incremental Conductance technique INC and the Modified Incremental Conductance technique "M-INC".

The results show that the proposed technique's overall tracking speed is 3.7 times faster than the conventional INC technique and 1.52 times faster than the modified INC technique. In addition, the tracking power losses with the proposed technique are lower compared to the other techniques. In terms of overall efficiency, the proposed technique is the most efficient with an efficiency of $94.83 \%$, followed by the modified technique with an overall efficiency of $87.94 \%$. The efficiency of the 
conventional INC technique is the lowest and does not exceed $83.33 \%$.

\section{Data AVAILABILITY}

The code Matlab developed and used to perform the proposed method is available from the corresponding author upon request.

\section{CONFLICTS OF INTEREST}

The authors declare that they have no conflicts of interest.

\section{FUNDING}

This research did not receive specific funding. This work is part of the research work of the university Abdelamek Essaidi.

\section{REFERENCES}

[1] Amir, A., Selvaraj, J., \& Rahim, N. A. (2016). Study of the MPP tracking algorithms: Focusing the numerical method techniques. Renewable and Sustainable Energy Reviews, 62, 350-371.

[2] Gupta, A., Chauhan, Y. K., \& Pachauri, R. K. (2016). A comparative investigation of maximum power point tracking methods for a solar PV system. Solar Energy, 136, 236-253.

[3] Hart, G. W., Branz, H. M., \& Cox, C. H. (1984). Experimental tests of open-loop maximum-power-point tracking techniques for photovoltaic arrays. Solar cells, 13(2), 185-195.

[4] Ram, J. P., Babu, T. S., \& Rajasekar, N. (2017). A comprehensive review on solar PV maximum power point tracking techniques. Renewable and Sustainable Energy Reviews, 67, 826-847.

[5] Sathyanarayana, P., Ballal, R., Sagar, P. L., \& Kumar, G. (2015). Effect of shading on the performance of solar PV panel. Energy and Power, 5(1A), 1-4.

[6] F. A. O. Aashoor and F. V. P. Robinson, "A variable step size perturb and observe algorithm for photovoltaic maximum power point tracking," in 2012 47th International Universities Power Engineering Conference (UPEC), pp. 1-6, London, UK, September 2012.

[7] ISALOO, B. Azizian et AMIRI, Parviz. Improved variable step size incremental conductance MPPT method with high convergence speed for PV systems. Journal of Engineering Science and Technology, 2016, vol. 11, no 4, p. 516-528.

[8] T. K. Soon and S. Mekhilef, "A fast-converging MPPT technique for photovoltaic system under fast-varying solar irradiation and load resistance," IEEE Transactions on Industrial Informatics, vol. 11, no. 1, pp. 176-186, 2015.

[9] S. Patel and W. Shireen, "Fast converging digital MPPT control for photovoltaic (PV) applications," in 2011 IEEE power and energy society general meeting, pp. 1-6, Detroit, MI, USA, July 2011.

[10] M. Sokolov and D. Shmilovitz, "Load line emulation based maximum power point tracking," in 2008 IEEE power electronics specialists conference, pp. 4098-4101, Rhodes, Greece, June 2008.

[11] T. Sruthy and F. Mohan, "Fast-converging MPPT technique for Photovoltaic system using dsPIC controller," in 2017 11th International Conference on Intelligent Systems and Control (ISCO), pp. 140-144, Coimbatore, India, January 2017.

[12] Fathabadi, H. (2016). Novel high efficiency DC/DC boost converter for using in photovoltaic systems. Solar Energy, 125, 2231.
[13] Santos, J. L., Antunes, F., Chehab, A., \& Cruz, C. (2006). A maximum power point tracker for PV systems using a high performance boost converter. Solar Energy, 80 (7), 772-778.

[14] R. W. Erickson and D. Maksimovic, Fundamentals of Power Electronics, Springer Science \& Business Media, 2007.

[15] Mohan, N., \& Undeland, T. M. (2007). Power electronics: converters, applications, and design. John Wiley \& Sons

[16] The European Technology Platform Smart Grids. Smart grids: strategic deployment document for Europe's electricity networks of the future n.d. 〈http://www.smartgrids.eu/documents/SmartGrids_SDD_FINAL_ APRIL2010. pdf).

[17] Erbs D.G., Klein S.A., Duffie J.A., (1982) : Estimation of the diffuse radiation fraction for hourly, daily and monthly-average global radiation. Solar Energy, 28, 293-304

[18] Loukriz, A., Haddadi, M., \& Messalti, S. (2016). Simulation and experimental design of a new advanced variable step size Incremental Conductance MPPT algorithm for PV systems. ISA Transactions, 62, 30-38.

[19] K. S. Tey and S. Mekhilef, "Modified incremental conductance algorithm for photovoltaic system under partial shading conditions and load variation," IEEE Transactions on Industrial Electronics, vol. 61, no. 10, pp. 5384-5392, 2014.

[20] K. S. Tey and S. Mekhilef, "Modified incremental conductance MPPT algorithm to mitigate inaccurate responses under fast changing solar irradiation level," Solar Energy, vol. 101, pp. 333 342, 2014.

[21] M. F. N. Tajuddin, S. M. Ayob, Z. Salam, and M. S. Saad, "Evolutionary based maximum power point tracking technique using differential evolution algorithm," Energy and Buildings, vol. 67, pp. 245-252, 2013.

[22] M. F. N. Tajuddin, M. S. Arif, S. M. Ayob, and Z. Salam, "Perturbative methods for maximum power point tracking (MPPT) of photovoltaic (PV) systems: a review," International Journal of Energy Research, vol. 39, no. 9, pp. 1153-1178, 2015.

[23] X. S. Li, H. Q. Wen, L. Jiang, W. Xiao, Y. Du, and C. Zhao, “An improved MPPT method for PV system with fast-converging speed and zero oscillation," IEEE Transactions on Industry Applications, vol. 52, no. 6, pp. 5051-5064, 2016

[24] A. Belkaid, I. Colakc, and O. Isik, "Photovoltaic maximum power point tracking under fast varying of solar radiation," Applied Energy, vol. 179, pp. 523-530, 2016.

[25] Teng JH. A direct approach for distribution system load flow solutions. IEEE Transactions on power delivery. $2003 \mathrm{Jul}$ 9;18(3):882-7. 